\title{
Fatigue performance evaluation of bitumen mastics reinforced with polyolefins through a dissipated energy approach
}

\author{
C. Roman, M.A. Delgado, M. García-Morales $\square$ \\ Departamento de Ingeniería Química, Centro de Investigación en Tecnología de Productos y Procesos Químicos (Pro2TecS), \\ Campus de "El Carmen", Universidad de Huelva, (Huelva -Spain) \\ $\triangle$ moises.garcia@diq.uhu.es
}

Received 8 July 2019

Accepted 27 November 2019

Available on line 17 March 2020

\begin{abstract}
Polymers are known to improve the fatigue resistance of asphalt mastics. However, undesirable results can be obtained if the polymer is not successfully integrated into the bitumen binder. The goal of this work is to evaluate the effect of the addition of three selected polyolefins on their mastic's fatigue performance. Low and high density polyethylenes (LDPE and HDPE) and polypropylene (PP) were chosen and used at the concentration of $4 \mathrm{wt} . \%$. A dissipated energy approach was used in order to analyze the fatigue resistance, at $25^{\circ} \mathrm{C}$, of the three composites studied. Dynamic time sweeps at and above the linear viscoelastic threshold were carried out. Based on that, the results demonstrated a better improvement when the LDPE was considered. For that binder, fluorescence optical microscopy observations at $25^{\circ} \mathrm{C}$ provided morphological evidence of a more homogeneous bitumen-polymer distribution which could be behind the improved fatigue behavior.
\end{abstract}

KEYWORDS: Fatigue; Rheology; Polymer; Microstructure; Characterization.

Citation/Citar como: Roman, C.; Delgado, M.A.; García-Morales, M. (2020) Fatigue performance evaluation of bitumen mastics reinforced with polyolefins through a dissipated energy approach. Mater. Construcc. 70 [338], e217 https://doi.org/10.3989/mc.2020.09319

RESUMEN: Evaluación del comportamiento a la fatiga de másticos bituminosos reforzados con poliolefinas a través de una metodología basada en energía disipada. El uso de polímeros mejora la resistencia a la fatiga de los másticos asfálticos. Sin embargo, se pueden obtener resultados no esperados si el polímero no se integra eficientemente en el ligante bituminoso. El objetivo de este trabajo es evaluar el efecto de la adición de 3 poliolefinas sobre el comportamiento a la fatiga. Se seleccionaron polietilenos de baja y alta densidad (PEBD y PEAD) y polipropileno (PP) que se usaron al $4 \%$ en peso. Se empleó una metodología basada en la energía disipada, a $25^{\circ} \mathrm{C}$. Se realizaron ensayos dinámicos de barrido de tiempo en el límite y por encima del intervalo de viscoelasticidad lineal, que demostraron un mejor comportamiento para el mástico que contenía PEBD. Para él, se observó a través de microscopía óptica de fluorescencia que la distribución de polímero en el betún era mucho más homogénea, y éste podría ser el motivo del comportamiento mejorado.

PALABRAS CLAVE: Fatiga; Reología; Polímero; Microestructura; Caracterización.

ORCID ID: C. Roman (https://orcid.org/0000-0002-7960-5832); M.A. Delgado (https://orcid.org/0000-0003-05737987); M. García-Morales (https://orcid.org/0000-0003-4153-487X)

Copyright: (C) 2020 CSIC. This is an open-access article distributed under the terms of the Creative Commons Attribution 4.0 International (CC BY 4.0) License. 


\section{INTRODUCTION}

Fatigue is one of the most important distresses experienced by flexible pavements during their service live. When the traffic applies repetitive load to the pavement surface, cracks may initiate from the bottom and propagate upwards until failure. In this process, the bituminous binder has been recognized as the major factor because it represents the leading media of energy dissipation in asphalt mixtures (1). Molecular mobility could play a significant role in the appearance of fatigue damage in bituminous materials (2). During the hot mix asphalt fabrication, fine mineral material present in the aggregates is incorporated into the binder forming the mastic. Thus, the mastic is the actual binder that holds the coarse aggregates together (3). Polymer-modified bitumens (PMBs) are often used such that fatigue and other pavement-related failures are delayed. The use of a list of different fibres in asphalt mixtures is also common $(4,5)$. In both cases, the resulting mastic is a ternary composite for which fatigue resistance characterization results fundamental.

Most of the studies conducted on fatigue damage in bituminous mastics are based on the so-called dissipated energy approach, which has also been applied to other materials like polymers, metals and composites (1). These studies are frequently carried out in stress-controlled mode $(6,7)$ for mixtures used in thick asphalt concrete layer and strain-controlled mode (8) for materials that are used in thin asphalt concrete layers. Some investigations have compared both modes of deformation $(1,9)$. Under stress-controlled mode, the dissipated energy per volume $\mathrm{W}_{\mathrm{n}}$ at every loading cycle " $\mathrm{n}$ " can be strictly calculated as Equation [1]:

$$
\mathrm{W}_{\mathrm{n}}=\int_{0}^{2 \pi / \omega} \sigma \cdot d \gamma
$$

Within the linear viscoelastic (LVE) range, the result of Equation [1] is given by Equation [2]:

$$
\mathrm{W}_{\mathrm{n}}=\pi \cdot \sigma_{0} \cdot \gamma_{\mathrm{n}} \cdot \sin \left(\delta_{\mathrm{n}}\right)
$$

where $\sigma_{0}$ is the stress amplitude imposed, $\gamma_{n}$ is the strain amplitude measured, and $\delta_{\mathrm{n}}$ is the phase angle $\left(0 \mathrm{rad}<\delta_{\mathrm{n}}<\pi / 2 \mathrm{rad}\right)$ between the input signal $\sigma(\mathrm{t})=$ $\sigma_{0} \cdot \sin (\omega \cdot \mathrm{t})$ and its output response $\gamma_{\mathrm{n}}(\mathrm{t})=\gamma_{\mathrm{n}} \cdot \sin (\omega \cdot \mathrm{t}-$ $\left.\delta_{n}\right)$. Equation [2] is also valid under strain-controlled mode as long as the imposed amplitude is $\gamma_{0}$ and the response is $\sigma_{\mathrm{n}}$

Even though not specifically mentioned, most of the published works on this field makes use of Equation [2] even if nonlinear conditions are tested (3) assuming that the first harmonic corresponding to the output signal has a much larger contribution if compared to the remaining odd harmonics (10).
Otherwise, computation of Equation [1] has to be done by means of Lissajous plots which are not always made available by commercial rheometers.

However, only a part of the dissipated energy comes from the crack formation and propagation, whilst the remaining part is associated to the viscoelastic nature of the sample $(11,12)$. So, the damage done to the material has to be evaluated by computing the difference in the dissipated energy between two consecutives loading cycles.

Based on the dissipated energy concept, a simple approach which allows predicting fatigue failure is the Dissipated Energy Ratio (DER) method $(3,6)$, calculated as the ratio of the cumulative dissipated energy up to cycle " $n$ " relative to the dissipated energy of cycle " $n$ ". When the function DER(n) is plotted, the cycle at which failure occurs can be determined at the point at which the curve deviates from a straight line. Unlike the Ratio of Dissipated Energy Change (RDEC) method, which provides unique relationships between the so-called "plateau value" and fatigue life $(1,9,13)$, the fatigue laws derived from the DER method depend on the loading conditions (mode, frequency, etc.). Even so, this method is an easy way to compare and discern between different materials in terms of fatigue resistance under same loading conditions. In our case, it allowed the effect of the type of polyolefin to be evaluated.

The vast majority of the existing fatigue studies on polymer-modified binders (either bitumen or mastic) are based on SBS or EVA $(1,6,8,14)$. Most of them pursue to derive fatigue laws without paying attention to the specific role of the polymer. They do not describe the prolonged fatigue life observed in terms of the polymer-bitumen microstructure. Few studies report the fatigue performance of bitumen modified with polyolefins even though these polymers have shown improved resistance to permanent deformation. Examples of the sustainable reuse of waste polyolefins as modifiers for asphalt binders can be found in $(15,16)$. Very often, little or no interest is shown in the polymer properties $(3,17,18)$. Some other works related to sustainable approaches in this field are worth mentioning (19-21).

Moreover, rest periods allow the material to recover from damage due to relaxation and selfhealing of micro-cracks. This phenomenon, which is not frequently taken into consideration at the experimental design, makes the number of cycles until failure, and so fatigue life, to increase (12). The importance of all these mechanisms is very well described in (22-25).

The objective of this work is to evaluate and compare the fatigue resistance of bituminous mastics modified with three different recycled polyolefins: LDPE, HDPE and PP. The results are based on the application of the dissipated energy concept 
to dynamic time sweep tests under stress-controlled or strain-controlled modes at the limit or beyond the linear viscoelastic (LVE) threshold, and a potential explanation to the behavior found is provided in terms of morphological observations by fluorescence optical microscopy.

\section{MATERIALS AND METHODS}

\subsection{Materials}

Two bitumens (A and $\mathrm{B}$ ) with penetrations at $25^{\circ} \mathrm{C}$ of 73 and $1791 / 10-\mathrm{mm}$, respectively, were selected as base material for polymer modification. A third neat bitumen with penetration at $25^{\circ} \mathrm{C}$ of 50 $1 / 10-\mathrm{mm}$, denoted as $\mathrm{C}$, was used as an unmodified control sample.

Three different types of recycled polyolefins were used as modifiers: low and high density polyethylenes (LDPE and HDPE, respectively) and polypropylene (PP). The polymers were provided in the form of pellets of $5 \mathrm{~mm}$. Their melting temperature $\left(T_{\text {melt }}\right)$ and crystalline fraction percentage $\left(\chi_{\text {cryst }}\right)$ are provided in Table 1.

The filler has an apparent density of $1.32 \mathrm{~g} / \mathrm{cm}^{3}$ and particle size below 100 microns. Table 2 presents its complete gradation. Its mineral composition is: Quartz (40 wt.\%), Clay minerals (35 wt.\%), Opaque minerals (10 wt.\%), Muscovite (5 wt.\%), Feldspars (5 wt.\%) and Carbonates (5 wt.\%). Before its use, moisture was completely removed by setting the filler in an oven at $120^{\circ} \mathrm{C}$ overnight.

\subsection{Processing of polymer modified bitumens (PMBs) and mastics}

PMBs were first prepared with a high-shear homogenizer at $5000 \mathrm{rpm}$, for 1.5 hours, and under optimized blending temperatures of 170,180 and $195^{\circ} \mathrm{C}$, for LDPE, HDPE and PP, respectively. This device was equipped with a square hole high shear screen, specifically suitable for dispersing molten polymers. In order to compare the effect of the polymer type, a fixed polymer concentration of $4 \mathrm{wt} . \%$ was chosen. When dealing with PBMs, fixing the polymer concentration and bitumen type whilst varying the polymer type may lead to PBMs with very different hardness which, undoubtedly, would affect the study. According to the approach reported by Roman and Garcia-Morales (26), it was opted to vary the source bitumen so as to maintain the PBMs penetration within a narrow interval. So, the hardest bitumen A was modified with LDPE, whilst the softest bitumen B was modified with HDPE or PP. Thus, all the binders used in the preparation of mastics presented penetrations within a narrow interval from 50 to $661 / 10-\mathrm{mm}$. The results of the PMBs penetration grade (UNE-EN 1426) and
TABLE 1. Selected properties of neat bitumens, polyolefins and their resulting blends.

\begin{tabular}{|c|c|c|c|}
\hline Bitumens and blends & $\begin{array}{l}T^{\mathrm{R} \& \mathrm{~B}} \\
\left({ }^{\circ} \mathrm{C}\right)\end{array}$ & $\begin{array}{l}\text { Pen. } \\
(1 / 10-\mathrm{mm})\end{array}$ & $\begin{array}{c}\phi_{\mathrm{PRP}} \\
(\mathrm{vol.} \%)\end{array}$ \\
\hline Base Neat bitumen-A & 45 & 73 & NA \\
\hline Base Neat bitumen-B & 40 & 179 & NA \\
\hline Neat bitumen-C (control) & 50 & 50 & NA \\
\hline Bitumen-A + 4 wt. $\%$ LDPE & 61 & 50 & 24.5 \\
\hline Bitumen-B + 4 wt. $\%$ HDPE & $>80$ & 62 & 22.6 \\
\hline Bitumen-B + 4 wt. $\%$ PP & 66 & 66 & 14.5 \\
\hline Polyolefins & \multicolumn{2}{|c|}{$\mathrm{T}_{\text {melt }}\left({ }^{\circ} \mathrm{C}\right)$} & $\chi_{\text {cryst }}(\%)$ \\
\hline LDPE & \multicolumn{2}{|c|}{$110.4 / 124.6$} & 29.2 \\
\hline HDPE & \multicolumn{2}{|c|}{132.4} & 47.5 \\
\hline $\mathrm{PP}$ & \multicolumn{2}{|c|}{164.2} & 35.7 \\
\hline
\end{tabular}

NA $=$ Non Applicable

$\phi_{\text {PRP }}=$ Polymer-rich phase volume fraction

$\mathbf{T}^{\mathbf{R} \& \mathbf{B}}=$ Ring-and-Ball softening temperature (UNE-EN 1427 standard)

Pen. $=$ Penetration grade at $25^{\circ} \mathrm{C}($ UNE-EN 1426 standard $)$

$\mathbf{T}_{\text {melt }}=$ polymer melting temperature

$\chi_{\text {cryst }}=$ polymer crystalline fraction percentage

TABLE 2. Filler gradation.

\begin{tabular}{lc}
\hline Sieve & Percent passing (by mass) \\
\hline $100-\mu \mathrm{m}$ & 100 \\
$75-\mu \mathrm{m}$ & 74 \\
$63-\mu \mathrm{m}$ & 51 \\
$40-\mu \mathrm{m}$ & 19 \\
\hline
\end{tabular}

Ring-and-Ball softening point (UNE-EN 1427) are shown in Table 1.

In order to assess the polymer swelling during the blending, bitumen-rich and polymer-rich phases were separated from the PMBs by their destabilization in tooth paste tubes (UNE-EN 13399) at $170{ }^{\circ} \mathrm{C}$. When the polymer-rich phase creamed up its volume fraction, $\phi_{\mathrm{PRP}}$, was calculated (Table 1).

After this first stage, mastics with a filler/binder ratio of $65 / 35$ by weight (about $60 / 40$ by volume) were obtained. The adequate amount of filler was added and mixed with the binders (PMBs or neat bitumen) for 1 extra hour, at $3500 \mathrm{rpm}$. The use of a specific dispersing tool for powders provided an effective dispersion.

\subsection{Materials testing}

First of all, the polyolefins were characterized by means of differential scanning calorimetry (DSC) runs at $5{ }^{\circ} \mathrm{C} / \mathrm{min}$, with a TA Instruments Q100 (USA) calorimeter. In order to erase previous thermal history, samples were always subjected 
to equilibration for 15 minutes above the polymer melting temperature.

As for the mastics, dynamic torsional time sweep tests were carried out at $25^{\circ} \mathrm{C}$, under stresscontrolled or strain-controlled modes. Although 10 $\mathrm{Hz}$ is a common frequency in fatigue tests, it is too high for a rheometer to give accurate results. For this reason the test frequency was set to $1 \mathrm{~Hz}$. The tests were carried out with the rheometer Physica MCR-301 (Anton Paar, Austria), featured with the Anton Paar SFR test fixture for torsion mode. Rectangular probes, prepared by compressionmolding (100 bar for $10 \mathrm{~min}$ ) at ambient temperature, were measured. The probes dimensions, as corresponding to Figure 1, were $\mathrm{L}=50 \mathrm{~mm}, \mathrm{~W}=10$ $\mathrm{mm}$ and $\mathrm{T}=2.8 \mathrm{~mm}$. The test temperature selection was conditioned by the fact that the fatigue tests could be greatly affected by plastic flow at higher temperatures than $25^{\circ} \mathrm{C}$ (27). Previously, amplitude sweep tests, at the same frequency, were performed so as to ascertain the critical values beyond which the linear viscoelastic response no longer remains. The evaluation procedure for the time sweep tests consisted of: i) an initial 5 mininterval of loading under a stress or strain within the LVE regime, which gave the values of the viscoelastic functions, $\left|\mathrm{G}^{*}\right|$ and $\delta$, associated to the unaltered state of the sample; ii) an intermediate 30 min-interval under a stress or strain outside the LVE regime, which yielded partial damage in the sample; iii) a final 30 min-interval under the same stress or strain applied in step i), over which the initial state is partially recovered (self-healing).
Dynamic shear time sweep tests at a frequency of $1 \mathrm{~Hz}$ and a temperature of $55^{\circ} \mathrm{C}$ were also conducted on the same rheometer with a plate-plate measuring system of radius $\mathrm{R}=12.5 \mathrm{~mm}$ and gap $\mathrm{h}=1 \mathrm{~mm}$, as corresponding to Figure 1. The goal was to evaluate the self-healing capability when the material is heated above the ambient temperature, hence, shear mode was required due to much lower viscoelastic moduli values.

At least three replicates were conducted for every sample and data shown (average) have statistically significant values, i.e. they did not exceed a significance level of 0.05 in Student's t-test and had a 95\% confidence interval.

Figure 1 presents schematic diagrams of the measuring systems: a) torsional mode and b) shear mode, along with the formulae provided by the manufacturer for the conversion of torque (M) into stress $(\sigma)$, and angular displacement $(\varphi)$ into strain $(\gamma)$ in the corresponding geometries, according to Equations [3] and [4]:

$$
\begin{gathered}
\sigma=\mathrm{K}_{\sigma} \cdot \mathrm{M} \\
\gamma=\mathrm{K}_{\gamma} \cdot \varphi
\end{gathered}
$$

Fluorescence optical microscopy, at room temperature, was carried out on the polymer-modified source binders. The characterization was conducted on samples prepared by the procedure described in EN-13632 (cryo-fracturing), which guarantees that morphology upon blending is not altered by

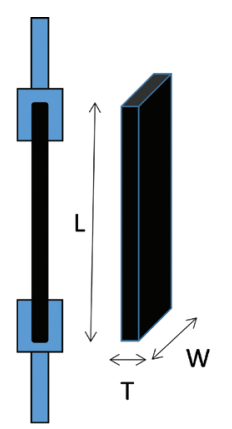

a) Torsion mode:

$$
K_{\sigma}=\frac{\mathrm{c}_{2}}{c_{1}} \cdot \frac{1}{W \cdot \mathrm{T}^{2}} ; K_{\gamma}=c_{2} \cdot \frac{\mathrm{T}}{L}
$$

where:

$$
c_{1}=\frac{1}{3}\left(1-\frac{0,630}{n}+\frac{0,052}{n^{5}}\right) ; \quad c_{2}=1-\frac{0,65}{1+n^{3}} ; \quad n=\frac{\mathrm{W}}{T}
$$

FIGURE 1. Schematic diagram of the a) torsion and b) shear modes measuring systems, along with the geometry factors for stress and strain calculations.

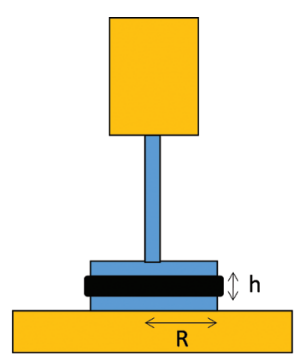

b) Shear mode:

$$
K_{\sigma}=\frac{2}{\pi \cdot \mathrm{R}^{3}} ; K_{\gamma}=\frac{\mathrm{R}}{h}
$$


subsequent handling. Representative morphology prototypes were assured by using, for each formulation studied, at least three different samples and taking five pictures at different locations. An optical microscope Olympus BX51 coupled with a metal halide lamp of $120 \mathrm{~W}$ was used.

\section{RESULTS AND DISCUSSION}

\subsection{Fatigue-resistance evaluation under strain-controlled mode}

In order to evaluate the linear viscoelastic (LVE) range of the mastics at $25^{\circ} \mathrm{C}$, dynamic amplitude sweeps at a constant frequency of $1 \mathrm{~Hz}$ were carried out in torsion mode. The onset of the non-linear region was taken as the point where the linear relationship between the input stress and the output strain no longer remains. The strain critical values were $1.3,0.2,0.1$ and $0.15 \%$-strain, for neat, LDPE, HDPE and PP mastics, respectively. The unmodified mastic was able to withstand the largest strain before the LVE was overcome, which does not necessarily imply the same trend in the fatigue behavior, as shown later below.

Then, a comparative evaluation of the fatigue resistance of neat and LDPE-modified bitumen mastics, under strain-controlled mode, was firstly conducted. Three values of strain were chosen for the fatigue tests. The first one corresponded to the onset of the non-linear region of the neat bitumen mastic, $1.3 \%$, and then two largest values of 2.5 and $5.0 \%$. This is a common approach adopted in this field. Otherwise, the material fatigue life can be extremely long $(1,3,11)$ or could even be below the so-called fatigue endurance limit (13).

For the sake of comparison, the same strain values were also applied to the $4 \mathrm{wt} \%$ LDPE mastic. Figure 2 illustrates the results of dynamic time sweep tests, at $25^{\circ} \mathrm{C}$, under strain-controlled mode, plotted as log-linear evolution of $\left|\mathrm{G}^{*}\right|$ versus time. Over the first 5 minutes a strain well below the LVE limit (stage-i) was applied such that the material stiffness was evaluated with no alteration of its intrinsic microstructure. Obviously, constant values of $\left|G^{*}\right|$ were obtained for every set, neat or LDPE mastics, of experiments. Subsequently, the strain imposed was increased up to the corresponding non-linear target values (stage-ii), and maintained during the following 30 minutes. An instant decay in $\left|G^{*}\right|$ is observed. This decay, referred to as $\mathrm{D}_{0}$ in Figure 2, is calculated as a percentage of $\left|\mathrm{G}^{*}\right|$ in stage-i. It depends on both the strain imposed and the type of mastic, and has been reported to be related to material conditioning (8) rather than real damage. In fact, this decay is disregarded in further dissipated energy calculations. Marked differences in $\mathrm{D}_{0}$ are observed between 1.3 and $2.5 \%$-strain

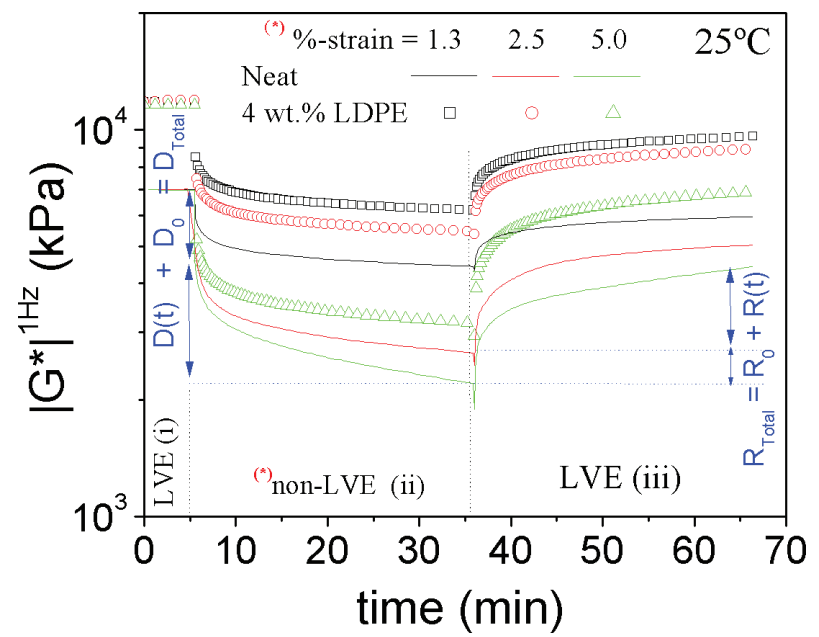

Figure 2. Dynamic time sweep tests, at $25^{\circ} \mathrm{C}$, in strain-controlled mode for the unmodified and LDPE-modified bitumen mastics studied.

for the neat mastic. As for the LDPE mastic, it was necessary a higher level of strain, $5.0 \%$, in order to appreciate important differences. Then, upon a short transient interval, a steady decreasing rate is observed. The decay associated to this period is referred to as $\mathrm{D}(\mathrm{t})$ in Figure 2, and it is also calculated as a percentage of $\left|G^{*}\right|$ in stage-i. Hence, the total decay percentage corresponding to stage-ii is calculated as $\mathrm{D}_{\text {Total }}=\mathrm{D}_{0}+\mathrm{D}(\mathrm{t})$. Moreover, it is noteworthy that the average slope corresponding to the time evolution of $\left|G^{*}\right|$ depends on both the strain imposed and the mastic type. For neat mastic, for example, the $\left|\mathrm{G}^{*}\right|$ curve corresponding to 1.3 $\%$-strain nearly levels off after 30 minutes, whilst $\left|\mathrm{G}^{*}\right|$ decreases much faster at $5.0 \%$-strain. Even so, fatigue fracture characterized by a dramatic drop in $\left|G^{*}\right|$ does not occur during the test, most probably because the total number of cycles was too low for the cracks to propagate (3). Eventually, selfhealing is noticed over the third stage (iii), when the material is returned to the LVE regime. The process takes place as a first instant recovery, $\mathrm{R}_{0}$, followed by a time-dependent recovery, $\mathrm{R}(\mathrm{t})$. Thus, $\mathrm{R}_{\text {Total }}=\mathrm{R}_{0}+\mathrm{R}(\mathrm{t})$ is the total recovery percentage corresponding to stage-iii, relative to the value of $\left|G^{*}\right|$ in stage-i. Comments are provided below, in next section, which compares the self-healing capability of the three polymer-modified bitumen mastics studied.

In terms of dissipated energy, the Dissipated Energy Ratio (DER) above described represents a simple method to assess the damage done to the material due to the continuous application of dynamic loading. First of all, the dissipated energy per volume $\mathrm{W}_{\mathrm{n}}$ at every loading cycle was calculated by Equation [2] above for neat and LDPE-modified mastics under \% $\%$-strain conditions of 1.3, 2.5 and 5. Under strain-controlled 
mode, $\mathrm{W}_{\mathrm{n}}$ decreases with time. Its evolution with the cycle number during stage-ii, which is presented in Figure $3 \mathrm{a}$, follows a decay pattern which can be fairly well represented by Equation [5]:

$$
\mathrm{W}(\mathrm{n})=\mathrm{W} 0+\mathrm{a} \cdot \mathrm{n}^{\mathrm{b}}+\mathrm{c} \cdot\left[1-\exp \left(-\frac{\mathrm{n}}{\mathrm{d}}\right)\right]
$$

The fitting parameters of the Equation [5] above, $\mathbf{W 0}, \mathbf{a}, \mathbf{b}, \mathbf{c}$ and $\mathbf{d}$, are gathered in Table 3 . From the calculated parameters, the total dissipated energy corresponding to stage-ii was analytically evaluated by Equation [6]:

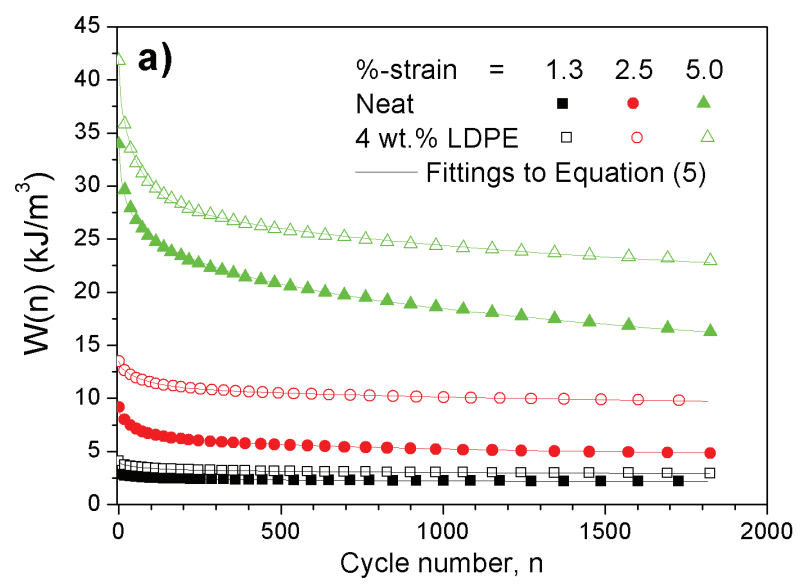

$$
\mathrm{W}_{\text {Total }}=\int_{0}^{\mathrm{N}} \mathrm{W}(\mathrm{n}) \cdot \mathrm{dn}
$$

with $\mathrm{N}$ being the total number of cycles, calculated as $\mathrm{N}=\mathrm{f} \cdot \mathrm{t}_{\mathrm{st}-\mathrm{i}}$, where $\mathrm{f}=1 \mathrm{~Hz}$, and $\mathrm{t}_{\text {st-ii }}$ is the stage-ii duration, in seconds. The computed values of $\mathrm{W}_{\text {Total }}$ for neat and LDPE-modified mastics at the three levels of deformation chosen are shown in Table 3.

It can be observed that oscillations at higher strain levels involve larger dissipated energies. Moreover, the LDPE-modified mastic presented larger dissipated energy values than the unmodified mastic. However, $\mathrm{W}_{\text {Total }}$ such as does not allow

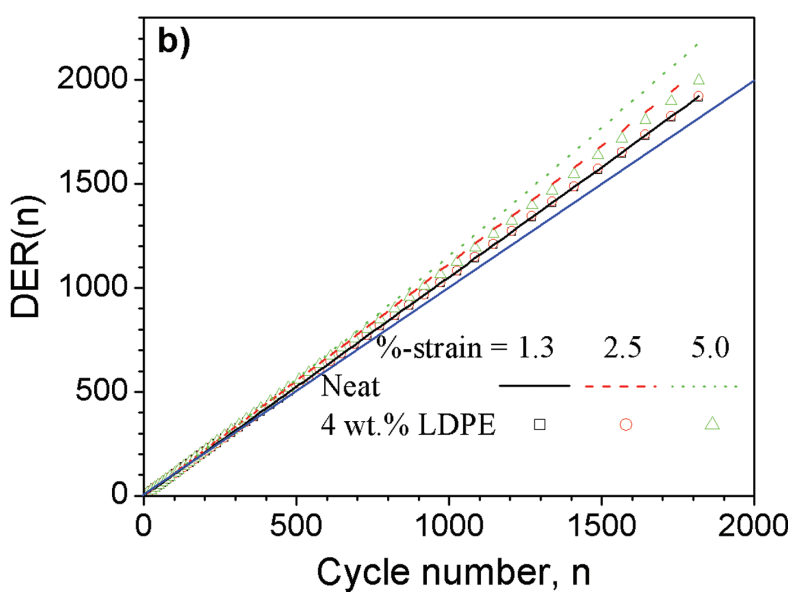

FIGURE 3. Evolution of a) dissipated energy and b) dissipated energy ratio with cycle number, at $25^{\circ} \mathrm{C}$, in strain-controlled mode, for the unmodified and LDPE-modified bitumen mastics studied.

\begin{tabular}{|c|c|c|c|c|c|c|c|c|}
\hline \multicolumn{9}{|c|}{ STRAIN-CONTROLLED TESTS } \\
\hline Sample & $\begin{array}{c}\text { Strain } \\
(\%)\end{array}$ & $\underset{\left(k J / m^{3}\right)}{\mathbf{W 0}}$ & $\begin{array}{c}a \\
\left(k J / m^{3}\right)\end{array}$ & $\begin{array}{c}\text { b } \\
(-)\end{array}$ & $\begin{array}{c}c \\
\left(\mathrm{~kJ} / \mathrm{m}^{3}\right)\end{array}$ & $\begin{array}{c}\text { d } \\
(-)\end{array}$ & $\begin{array}{c}\mathbf{W}_{\text {Total }} \\
\left(\mathbf{M J} / \mathbf{m}^{3}\right)\end{array}$ & $\begin{array}{c}\mathbf{p}\left(\times 10^{7}\right) \\
(-)\end{array}$ \\
\hline Neat & 1.3 & 2.84 & -4.050 & 0.026 & 4.231 & 1.330 & 4.093 & 0.172 \\
\hline Neat & 2.5 & 9.16 & -10.325 & 0.045 & 10.133 & 0.156 & 9.874 & 0.362 \\
\hline Neat & 5 & 33.94 & -7.863 & 0.155 & 7.381 & 0.0040 & 35.339 & 0.608 \\
\hline LDPE & 1.3 & 4.07 & -0.121 & 0.252 & -0.351 & 70.702 & 5.573 & 0.2 \\
\hline LDPE & 2.5 & 13.50 & -0.235 & 0.308 & -1.384 & 76.620 & 18.647 & 0.218 \\
\hline LDPE & 5 & 41.80 & -2.055 & 0.238 & -6.756 & 57.313 & 45.673 & 0.354 \\
\hline \multicolumn{9}{|c|}{ STRESS-CONTROLLED TESTS } \\
\hline Sample & $\begin{array}{l}\text { Stress } \\
(\mathbf{k P a})\end{array}$ & $\begin{array}{c}\mathrm{W0} \\
\left(\mathbf{k J} / \mathbf{m}^{3}\right)\end{array}$ & $\underset{\left(\mathrm{kJ} / \mathrm{m}^{3}\right)}{\mathrm{a}}$ & $\begin{array}{c}\text { b } \\
(-)\end{array}$ & $\begin{array}{c}c \\
\left(\mathrm{~kJ} / \mathrm{m}^{3}\right)\end{array}$ & $\begin{array}{c}\text { d } \\
(-)\end{array}$ & $\begin{array}{c}\mathbf{W}_{\text {Total }_{3}} \\
\left(\mathbf{M J} / \mathbf{m}^{3}\right)\end{array}$ & $\begin{array}{c}\mathbf{p}\left(\times 10^{7}\right) \\
(-)\end{array}$ \\
\hline LDPE & 60 & 1.06 & 0.0064 & 0.474 & 0.134 & 86.976 & 2.41 & 0.242 \\
\hline LDPE & 90 & 2.72 & 0.026 & 0.498 & 0.544 & 101.028 & 7.118 & 0.421 \\
\hline LDPE & 130 & 5.39 & 0.069 & 0.524 & 1.778 & 117.790 & 16.821 & 0.605 \\
\hline LDPE & 250 & 26.08 & 0.177 & 0.751 & 14.446 & 86.066 & 122.495 & 1.684 \\
\hline HDPE & 60 & 4.16 & 0.074 & 0.460 & 1.349 & 95.617 & 12.665 & 0.471 \\
\hline HDPE & 90 & 10.02 & 0.216 & 0.497 & 4.280 & 106.109 & 36.023 & 0.684 \\
\hline $\mathrm{PP}$ & 60 & 4.43 & 0.101 & 0.467 & 0.375 & 57.709 & 12.722 & 0.682 \\
\hline PP & 90 & 10.51 & 0.022 & 0.852 & 3.641 & 77.379 & 37.91 & 1.633 \\
\hline
\end{tabular}

TABLE 3. Fitting parameters for Equation [5]; values of total dissipated energy and p-parameter for tests in Figures 3a and 5a. 
drawing conclusions on the fatigue resistance as it does not provide detailed information on how the dissipation has evolved. A parameter p computing the norm of the dissipated energy variation rate (calculated at the steady zone of stage-ii) relative to the total dissipated energy involved, according to Equation [7]:

$$
\mathrm{p}=\left|\frac{1}{\mathrm{~W}_{\text {Total }}} \cdot \frac{\mathrm{dW}(\mathrm{n})}{\mathrm{dn}}\right|
$$

can be a good first estimate on the effect of the polymer type on the fatigue resistance ( $p$ values are included in Table 3). A similar parameter $\mathrm{a}_{\mathrm{w}}$ is reported by Artamendi and Khalid (28). Higher values of the calculated parameter $\mathbf{p}$ suggest that the unmodified mastic is more fatigue-susceptible that the LDPE-modified mastic. Further, the DER(n) function was analytically evaluated according to Equation [8]:

$$
\operatorname{DER}=\int_{0}^{\mathrm{n}} \frac{\mathrm{W}(\mathrm{n}) \cdot \mathrm{dn}}{\mathrm{W}_{\mathrm{n}}}
$$

When DER(n) is plotted versus the cycle number, $n$, as shown in Figure $3 b$ for the neat and LDPE mastics at $25^{\circ} \mathrm{C}$, the larger the deviation above a straight line with slope of 1 , the higher the damage. As can be seen, and in agreement with the previous calculated parameter, both mastics exhibit a similar response at $1.3 \%$-strain. However, the application of $2.5 \%$-strain on the neat mastic entails a deviation which is equivalent to the application of $5 \%$-strain on the LDPE-modified mastic. Finally, $5 \%$-strain on the unmodified mastic yields, by far, the largest deviation. Hence, Figure $3 \mathrm{~b}$ makes clear the neat mastic supports lower amount of load cycles than the LDPE modified mastic. It is worth mentioning that in a strain controlled mode tests under a specific strain percentage, the amount of energy introduced per load cycle in stiffer materials is higher than in softer materials. In that sense, this may be the cause for a material to support lower amount of load cycles than another one, and not necessarily a lower resistance to fatigue. Figure 2 demonstrate higher values of $\left|G^{*}\right|$ (higher stiffness) for the 4 wt.\% LDPE mastic which still withstands a higher number of load cycles. In consequence, the above statement allows concluding that the LDPE addition is enhancing the fatigue failure resistance of the mastic.

\subsection{Fatigue-resistance and self-healing analysis under stress-controlled mode}

As above referenced, some works which develop dissipated energy approaches based on stress-controlled measurements are also available. Compared to strain-controlled mode, Artamendi and Khalid (28) reported faster rate of damage for a stresscontrolled test using a stress amplitude value which caused initially the same value of strain amplitude. This may be explained based on the supplied energy per cycle. Thus, in stress controlled mode the energy per load cycle is constant, whilst in strain controlled mode the energy per load cycle decreases because the stress required to sustain the specified strain is reduced due to the damage produced in the material. In consequence, the fatigue failure is delayed. Figure 4 looks further into this matter. For a strain amplitude of $5 \%$ to be initially attained on the 4 wt.\% LDPE mastic, a stress amplitude of $250 \mathrm{kPa}$ has to be imposed.

Both tests yielded similar instant decays $\mathrm{D}_{0}$, but the decreasing rate during stage-ii (no-LVE period) was much higher under stress-controlled mode. In one of the earliest attempts to characterize fatigue cracking based on the concept of dissipated energy, Van Dijk et al. (29) concluded that for a given material and temperature the total dissipated energy until fatigue failure is constant and independent of the loading history. In our case, the total dissipated energy after the $\mathrm{N}$ cycles corresponding to stageii was calculated in both cases, showing values of 45.67 and $122.49 \mathrm{MJ} / \mathrm{m}^{3}$ for strain-controlled and stress-controlled, respectively (Table 3). If the Van Dijk and co-workers' hypothesis is valid, the result indicates that the number of cycles until failure will be lower under stress-controlled mode, that is, stress-controlled mode accelerates the fatigue process. The same conclusion was drawn by Artamendi and Khalid (28) who attributed shorter lives under stress-controlled mode to higher rates of cracking propagation. Later studies suggest that the total

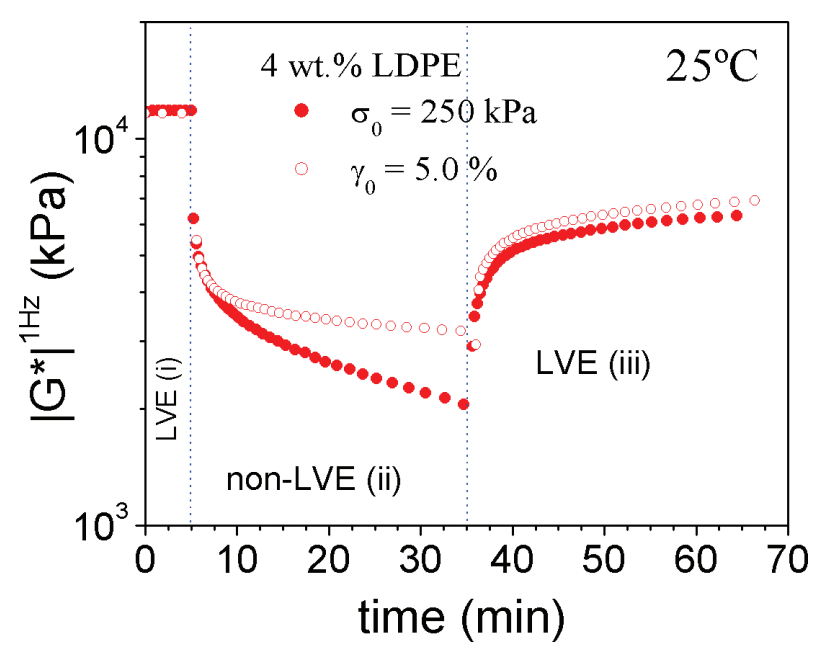

FIGURE 4. Evaluation of the dynamic time-dependent behavior, at $25^{\circ} \mathrm{C}$, for the LDPE-modified bitumen mastic, under comparable strain-controlled and stress-controlled initial conditions. 
dissipated energy is unable to properly describe the fatigue phenomenon in asphalt materials, as it does not distinguish between damage and intrinsic viscous effects. Even so, values of 0.354 and 1.684 in Table 3 for the above defined parameter $\mathbf{p}$, for straincontrolled and stress-controlled modes, respectively, allows concluding on the more severe stress-controlled loading effect. When the LVE conditions are re-established, the mastic self-healing is such that the $\left|G^{*}\right|$ recovery potential is barely affected by the mode of deformation, demonstrating that in no case fatigue failure has arisen.

Further, a comparative evaluation of the fatigue resistance of the three types of polyolefin-modified mastics studied was carried out by dynamic time sweep tests at $25^{\circ} \mathrm{C}$ under stress-controlled mode. The choice of this mode of deformation was based on subjecting the mastics to the most severe conditions such that the effect of polymer type is stressed. The selected stress values were 60 and $90 \mathrm{kPa}$. Additionally, the LDPE-modified mastic was also subjected to 130 and $250 \mathrm{kPa}$. As above, the dissipated energy per cycle was calculated by Equation [2] and its evolution with the cycle number during stage-ii is shown in Figure 5a.

Under stress-controlled mode, the dissipated energy varies with the cycle number according to an increasing profile which can also be described by Equation [5]. The five fitting parameters involved are gathered in Table 3. The values of average dissipated energy variation rate relative to the total dissipated energy were computed as above, and are presented in Table 3. According to this parameter, the PP-modified mastic shows the highest fatigue-sensitivity and the LDPE-modified mastic the lowest. The DER approach illustrated in Figure 5b leads to the same conclusion. At both 60 and $90 \mathrm{kPa}$, the PP-modified mastic presents larger deviations below a straight line with slope of 1 than the two other mastics under the same load level. The performance of the HDPE-modified mastic under $90 \mathrm{kPa}$ is equivalent to the LDPEmodified mastic under $130 \mathrm{kPa}$, whilst the response of the PP-modified mastic under $90 \mathrm{kPa}$ is equivalent to the LDPE-modified mastic under $250 \mathrm{kPa}$. These observations are in agreement with the $\mathbf{p}$ values in Table 3.

Based on the evolution of $\left|\mathrm{G}^{*}\right|$ with time, at $25^{\circ} \mathrm{C}$, under stress-controlled mode for the three polyolefin-modified bitumen mastics, the percentages of decay $\mathrm{D}_{\text {Total }}$ and recovery $\mathrm{R}_{\text {Total }}$ were obtained from stage-ii and stage-iii, respectively. According to the calculated ratio $\mathrm{R}_{\text {Total }} / \mathrm{D}_{\text {Total }}$ shown in Figure $6 \mathrm{a}$, the LDPE mastic presents, at $25^{\circ} \mathrm{C}$, the highest level of recovery after 30 minutes under LVE conditions. This result is probably a consequence of a microstructure which has been less damaged by the repetitive loading, as proposed in next section. In no case, the healing process is complete at the end of the LVE period.

The recovery ratios decreased as the stress applied increased, because the material requires more time to heal. The ratios $\mathrm{D}_{0} / \mathrm{D}_{\text {Total }}$ and $\mathrm{R}_{0} / \mathrm{R}_{\text {Total }}$ were also calculated. They demonstrated to be almost independent on the stress applied and so average values are presented in Figure 6b. The HDPE mastic was the most affected by the instant decay, proving to be more sensitive to the initial conditioning. The LDPE underwent the fastest initial recovery. Moreover, the healing process is believed to be controlled by the viscosity of the bitumen-rich phase (30) which strongly depends on temperature. Thus, dynamic shear time sweep tests were accomplished at $55^{\circ} \mathrm{C}$ so as to conduct experiments at a temperature which accelerates healing. In order to establish a comparative assessment, normalized $\left|\mathrm{G}^{*}\right|_{\mathrm{N}}$ curves (relative
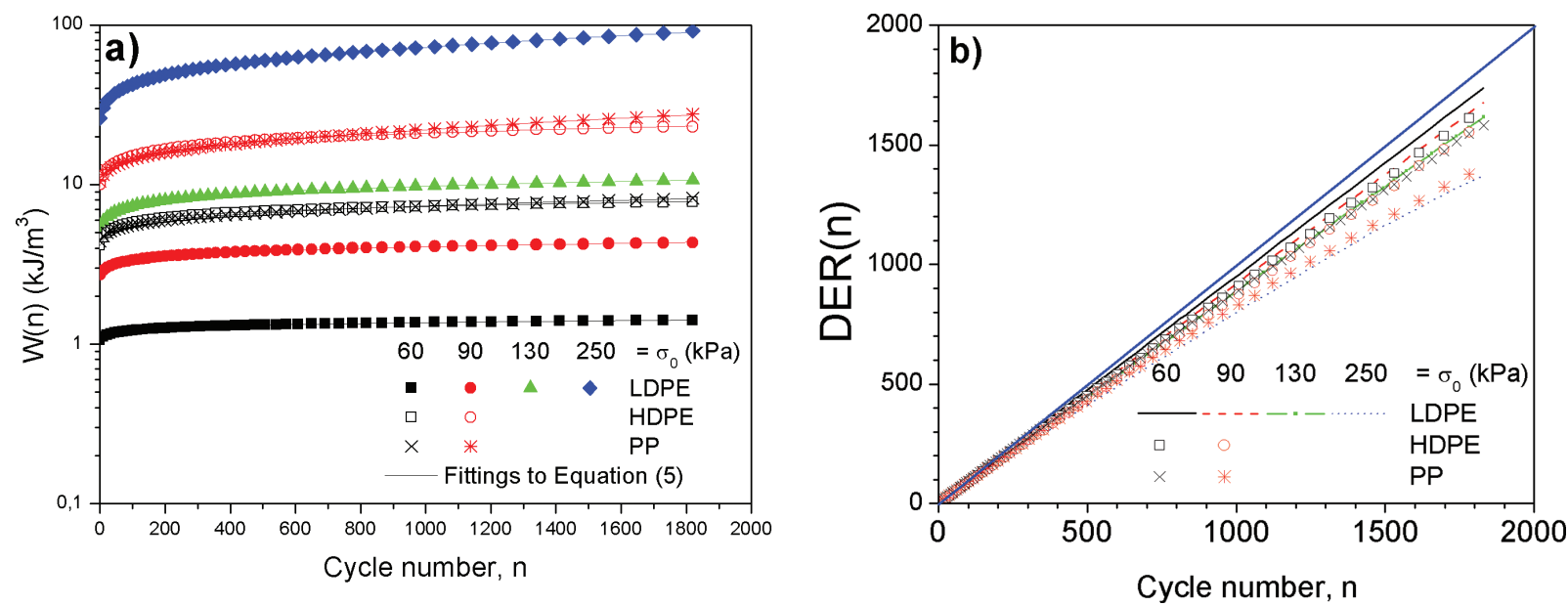

FIGURE 5. Evolution of a) dissipated energy and b) dissipated energy ratio with cycle number, at $25^{\circ} \mathrm{C}$, in stress-controlled mode, for the polymer-modified bitumen mastics studied. 
Fatigue performance evaluation of bitumen mastics reinforced with polyolefins through a dissipated energy approach $\bullet 9$
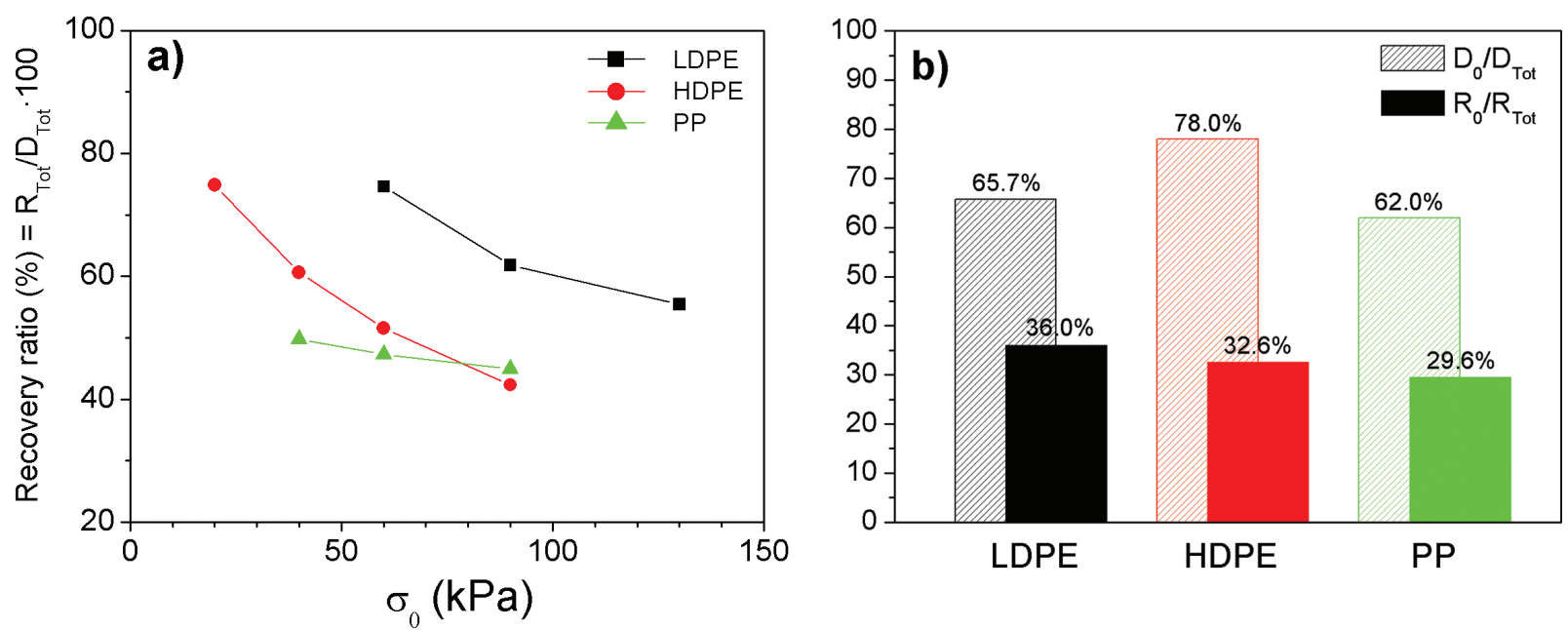

FIGURE 6. a) Stress dependency of the recovery ratio percentage $\mathrm{R}_{\text {Total }} / \mathrm{D}_{\text {Total }}$ as a function of the polymer type; b) Values of the ratios $D_{0} / D_{\text {Total }}$ and $R_{0} / R_{\text {Total }}$ for the polymer-modified bitumen mastics studied.

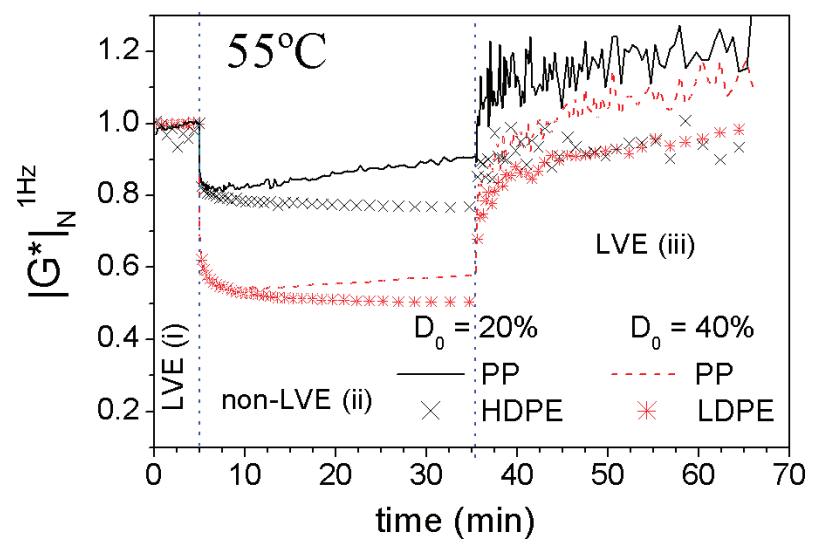

FIGURE 7. Dynamic time sweep tests, in the form of normalized $\left|\mathrm{G}^{*}\right|$, at $55^{\circ} \mathrm{C}$, in stress-controlled mode for the polymer-modified bitumen mastics studied.

to unperturbed LVE complex modulus values) are illustrated in Figure 7.

Stress amplitudes which provoked similar initial decays of 20 and $40 \%$ were chosen. When the LDPE-modified mastic was subjected to an initial decay of $40 \%,\left|G^{*}\right|_{N}$ almost levels off and then recovers nearly $100 \%$. In the case of PP-modified mastic, unexpectedly, the instant decay is followed by an increase in the complex modulus during stageii such that $\left|G^{*}\right|_{N}$ at the end of stage-iii is higher than the initial value. A higher effect is observed when the PP-modified mastic was subjected to $40 \%$ initial decay. This phenomenon was explained by Isailovic et al. (12) in terms of rearrangements within the material which induce improved mechanical properties. Such rearrangements are similar to what is observed during an asphalt mix maturing process.

\subsection{Effect of the quality of polymer dispersion}

Many studies which address the specific role of the polymer in the PMBs performance describe the results in terms of polymer properties like melt flow index, crystallinity or functional groups content (31). This approach, though, might not be successful if the polymer is not properly dispersed. A quick view to Table 3 for the three polyolefin-modified mastics under $90 \mathrm{kPa}$ allows concluding on the worst fatigue performance of the PP-mastic ( $\mathrm{p}=$ 1.633) as compared, for example, to the HDPEmastic $(p=0.684)$, both of them having the same polymer content and source bitumen. However, polypropylene is reported to exhibit better fatigue resistance than high density polyethylene. When dealing with polyolefin-modified bitumens, finding an explanation can be, a priori, more complicated due to the presence of two materials (polyolefin and bitumen) with low mutual compatibility. As reported by Yousefi (32), a description of the PMBs performance in terms of their dual-phase microstructure rather than the polymer structural parameters themselves stands for a much better approach in this case. Hence, an explanation to the worst fatigue performance of PP can be provided on these terms. The PP-modified bitumen is highly unstable, and its behavior is affected by the high rate of polymer segregation. Moreover, the different swelling degree during the blending of polymer and bitumen is also involved. During such a process, the polymer is swollen by the bitumen lightest fractions (referred to as "polymer-rich phase", PRP) and so bitumen results more concentrated in the heaviest fractions that the original one (termed "bitumen-rich" phase, BRP), as explained elsewhere (33). After blending, a PMB 
eventually consists of two separate phases, PRP and BRP. For the two above polyolefins, when 4 wt. \% was added to bitumen, they underwent volume increases up to 22.6 and 14.5 vol. \% for HDPE and PP, respectively ( $\phi_{\mathrm{PRP}}$ in Table 1$)$. It is clear that the PP incorporates much less amount of bitumen lightest compounds (saturates and aromatics) than the two other polyolefins, due most probably to a higher melt viscosity at the blending temperature. In consequence, the smaller extent of the polymerrich phase influenced the mastic fatigue resistance because the micro-cracks originate within the most fatigue-sensitive bitumen-rich phase which is larger in the PP-modified binder. This fact also explains the high self-healing capability observed at $55^{\circ} \mathrm{C}$ in the PP-modified mastic. Lower absorption of light bitumen components by the PP polymer-rich phase prevents bitumen-rich phase hardening (lower viscosity) what facilitates the internal structure rearrangement (30).

However, LDPE-mastic performs better than the HDPE-mastic, even though its corresponding $\phi_{\mathrm{PRP}}$ value is very similar (24.5 vol.\%). Fluorescence optical microscopy observations were made on the mastics, but no conclusion could be drawn because of the high filler content. However, observations on the polymer-modified bitumen phase in Figure 8 may shed light on the issue.

The LDPE-rich phase in Figure 8a demonstrates a much better level of dispersion than the HDPE-rich phase in Figure 8b. In that sense, Yousefi (32) reported that polyethylenes with short or branched chains are more easily dispersed in bitumen. Heating DSC scans conducted at a rate of $5{ }^{\circ} \mathrm{C} / \mathrm{min}$ revealed that the three polyolefins studied present a melting event associated to their crystalline region. The values of melting temperatures $\left(\mathrm{T}_{\text {melt }}\right.$ in Table 1$)$ are $110.4 / 124.6{ }^{\circ} \mathrm{C}$ for LDPE (which also contains a LLDPE fraction), $132.4{ }^{\circ} \mathrm{C}$ for HDPE and $164.2^{\circ} \mathrm{C}$ for PP. The crystalline fraction percentages $\left(\chi_{\text {cryst }}\right.$ in Table 1$)$ were computed from the specific crystallization enthalpies of the polyolefins studied and the theoretical value associated to pure crystalline polyolefins, as reported in Roman and Garcia-Morales (26). The results were $29.2 \%$ for LDPE, $47.5 \%$ for HDPE and $35.7 \%$ for PP. As expected, the LDPE/LLDPE blend crystalline fraction is much lower than that corresponding to HDPE, because LDPE consists of branched backbone chains. LDPE molecular architecture facilitates its dispersion in bitumen, in such a way that, if compared to HDPE, it yields a polymer-bitumen emulsion with reduced droplet size and improved stability, as observed by fluorescence optical microscopy. The direct consequence is that the extent of propagation of a micro-crack arisen within the bitumen-rich fraction is partially restrained by the small separation between adjacent polymer droplets, so, enhancing fatigue resistance.
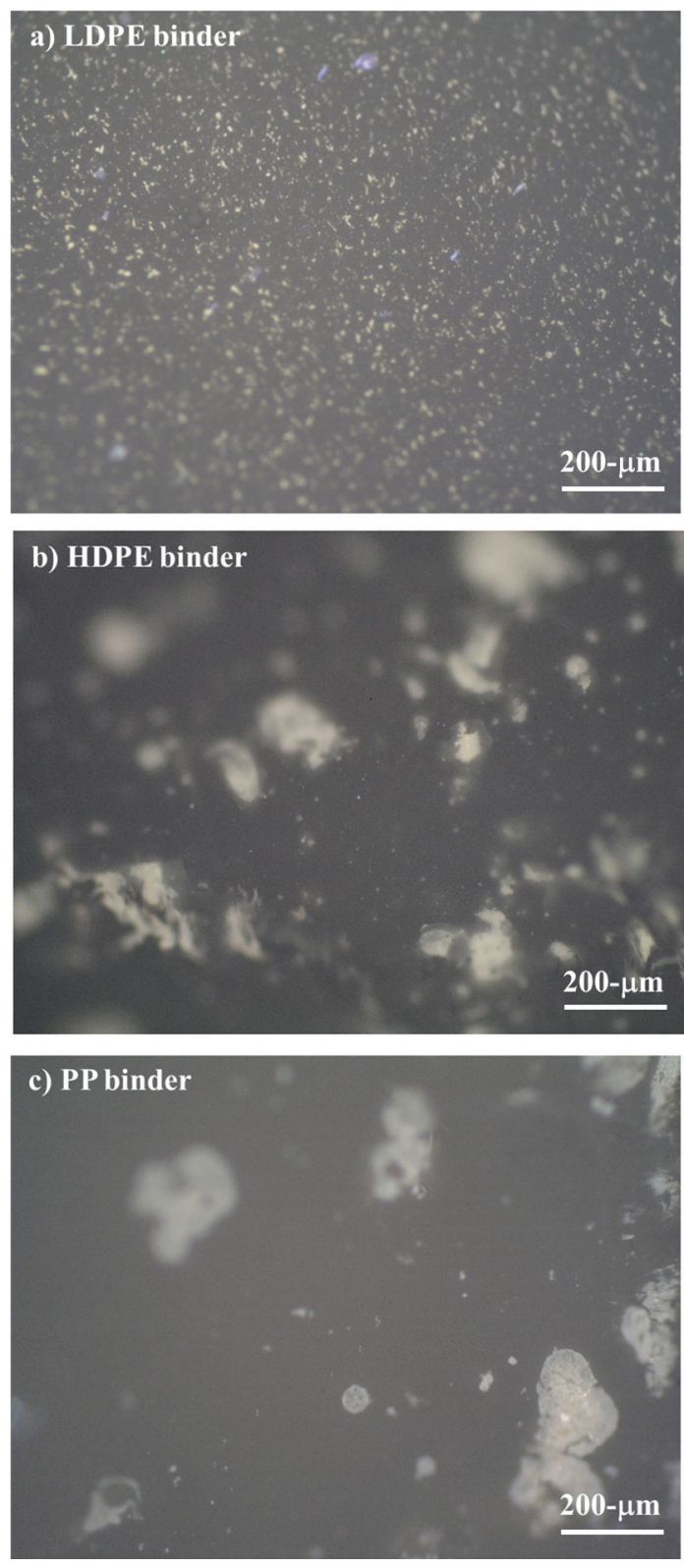

FIGURE 8. Fluorescence optical microscopy observations, at $25^{\circ} \mathrm{C}$, on the polymer-modified bitumens.

Furthermore, Figure 8c corroborates the smaller level of swelling associated to the PP-rich phase if compared, for example, to the HDPE-rich phase extent illustrated in Figure 8b. This observation further supports the above comments on the worst PP-modified mastic performance at ambient temperature, and its facility for self-healing when is subjected to temperatures close to its softening temperature. Studies on the potential influence provoked by source bitumens with different SARAs fractions (chemical compositions) are still required as future work. 


\section{CONCLUSIONS}

A dissipated energy approach was used to evaluate the fatigue resistance of three polyolefin-modified bitumen mastics at $25^{\circ} \mathrm{C}$. First, strain-controlled tests demonstrated that bitumen modification with 4 wt.\% LDPE enhances the mastic fatigue resistance if compared to an unmodified bitumen with equivalent hardness. Further studies on the effect of the polyolefin type were conducted under stresscontrolled mode, which accelerates fatigue and emphasizes the differences among the samples. The PP-modified mastic showed the lowest fatigue resistance and the LDPE-modified mastic the highest. Polymer swelling during the blending may explain the behavior observed. The PP-modified mastic behavior can be related to a smaller polymer-rich phase, 14.5 vol. $\%$, if compared to LDPE and HDPE, with 24.5 and 22.6 vol.\%, respectively. Under comparable swelling degrees in LDPE and HDPE mastics, the better performance of the former may be associated to its good dispersion in bitumen, as demonstrated by optical microscopy observations at $25^{\circ} \mathrm{C}$. The results have important practical implications in terms of pavement engineering. It is not possible to avail of the full potential provided by a polymer if its dispersion in the bitumen phase is poor, which may lead to unexpected and undesirable performance. Homogeneous dispersions can mitigate the propagation of micro-cracks within the bitumen-rich domains, which are restrained by the neighboring polymer droplets. Bitumen-polymer interactions, hence, play a role in the fatigue behavior of the resulting mastic binders.

\section{REFERENCES}

1. Shen, S.; Airey, G.D.; Carpenter, S.H.; Huang, H. (2006) A Dissipated Energy Approach to Fatigue Evaluation. Road Mater. Pavement Des. 7 [1], 47-69. https://doi.org/10.1080/ 14680629.2006.9690026

2. Moreno-Navarro, F.; Rubio-Gámez, M.C. (2016) A review of fatigue damage in bituminous mixtures: Understanding the phenomenon from a new perspective. Constr. Building Mater. 113, 927-938. https://doi.org/10.1016/j. conbuildmat.2016.03.126.

3. Frigio, F.; Ferrotti, G.; Cardone, F. (2016) Fatigue rheological characterization of polymer-modified bitumens and mastics. In: Proceedings 8th RILEM International Symposium on Testing and Characterization of Sustainable and Innovative Bituminous Materials, RILEM Bookseries 11, (2016), 655-666.

4. Slebi-Acevedo, C.J.; Pascual-Muñoz, P.; Lastra-González, P.; Castro-Fresno, D. (2019) A multi-criteria decision-making analysis for the selection of fibres aimed at reinforcing asphalt concrete mixtures. Int. J. Pavement Eng. https:// doi.org/10.1080/10298436.2019.1645848.

5. Slebi-Acevedo, C.J.; Lastra-González, P.; PascualMuñoz, P.; Castro-Fresno, D. (2019) Mechanical performance of fibers in hot mix asphalt: A review. Constr. Build. Mat. 200, 756-769. https://doi.org/10.1016/j. conbuildmat.2018.12.171.

6. Santagata, E.; Baglieri, O.; Dalmazzo, D. (2008) Experimental investigation on the fatigue damage behaviour of modified bituminous binders and mastics. In:
Asphalt paving technology, Association of asphalt paving technologists - Proceedings of the technical sessions 77, (2008), 851-883.

7. Maggiore, C.; Grenfell, J.; Airey, G.D. (2012) Evaluation of Fatigue Life Using Dissipated Energy Methods. In: 7th RILEM International Conference on Cracking in Pavements, RILEM Bookseries 4, (2012), 643-652.

8. Micaelo, R.; Pereira, A.; Quaresma, L.; Cidade, M.T. (2015) Fatigue resistance of asphalt binders: Assessment of the analysis methods in strain-controlled tests. Constr. Build. Mat. 98, 703-712. https://doi.org/10.1016/j. conbuildmat.2015.08.070.

9. Yuan, M-M.; Zhang, X-N.; Chen W-Q.; Zhang, S-X. (2013) Ratio of Dissipated Energy Change-based Failure Criteria of Asphalt Mixtures. Res. J. Appl. Sci. Eng. Tech. 6 [14], 2514-2519. https://doi.org/10.19026/rjaset.6.3731.

10. Hyun, K.; Wilhelm, M.; Klein, C.O.; Cho, K.S.; Nam, J.G.; Ahn, K.H.; Lee, S.; Ewoldt, R.H.; Mckinley, G.H. (2011) A review of nonlinear oscillatory shear tests: Analysis and application of large amplitude oscillatory shear (LAOS). Prog. Polym. Sci. 36 [12], 1697-1753. https://doi. org/10.1016/j.progpolymsci.2011.02.002

11. Teixeira Franco Castelo Branco, V. (2008) A unified method for the analysis of nonlinear viscoelasticity and fatigue cracking of asphalt mixtures using the dynamic mechanical analyzer, Texas A\&M University PhD Dissertation.

12. Isailovic, I.; Cannone-Falchetto, A.; Wistuba, M.P. (2015) Investigation of asphalt recovery properties in fatigue test with single rest period. In: Proceedings of the $6^{\text {th }}$ International Conference on Bituminous Mixtures and Pavements (Thessaloniki), (2015), 373-378

13. Shen, S.; Carpenter, S.H. (2005) Application of the Dissipated Energy Concept in Fatigue Endurance Limit Testing. Transp. Res. Record: J. Transp. Res. Board 1929 [1], 165-173. https://doi.org/10.1177/03611 98105192900120

14. Guglielmo, J.; Peebles, G.; Mehta, Y. (2014) Evaluation of Fatigue Behavior of Neat and Polymer Modified Binders and Mastics Using Multiple Test Methods. In: Proceedings of 29th International Conference on Solid Waste Technology and Management (Philadelphia), 2014.

15. Brasileiro, L.; Moreno-Navarro, F.; Tauste, R.; Matos, J.; Rubio-Gámez, M.C. (2019) Reclaimed Polymers as Asphalt Binder Modifiers for More Sustainable Roads: A Review. Sustainability 11 [3], 646. https://doi.org/10.3390/ su11030646.

16. Garcia-Trave, G.; Tauste, R. Moreno-Navarro, F; Sol-Sánchez, M.; Rubio-Gámez, M.C. (2016) Use of Reclaimed Geomembranes for Modification of Mechanical Performance of Bituminous Binders. J. Mater. Civ. Eng. 28 [7], 04016021. https://doi.org/10.1061/(ASCE) MT.1943-5533.0001507.

17. Brovelli, C.; Crispino, M.; Pais, J.C.; Pereira, P. (2014) Assessment of Fatigue Resistance of Additivated Asphalt Concrete incorporated Fibers and Polymers. J. Mater. Civ. Eng. 26 [3], 554-558. https://doi.org/10.1061/(ASCE) MT.1943-5533.0000837.

18. López-Montero, T.; Miró, R. (2017) Ageing and temperature effect on the fatigue performance of bituminous mixtures. Mater. Construcc. 67 [327], e126. https://doi. org/10.3989/mc.2017.04216.

19. Jiménez del Barco-Carrión, A.; García-Travé, G.; MorenoNavarro, F.; Martínez-Montes, G.; Rubio-Gámez, M.C. Comparison of the effect of recycled crumb rubber and polymer concentration on the performance of binders for asphalt mixtures. Mater. Construcc. 66 [323], e090. https:// doi.org/10.3989/mc.2016.08815.

20. Lacalle-Jiménez, H.I.; Edwards, J.P.; Thom, N.H. (2017) Analysis of stiffness and fatigue resistance of cold recycled asphalt mixtures manufactured with foamed bitumen for their application to airfield pavement design. Mater. Construcc. 67 [327], e127. https://doi.org/10.3989/ mc.2017.04616.

21. Moreno-Navarro, F.; Rubio-Gámez, M.C.; TomásFortún, E.; Valor-Hernández, F.; Ramírez-Rodríguez, A. (2014) Evaluation of the fatigue macro-cracking 
behavior of crumb rubber modified bituminous mixes. Mater. Construcc. 64 [315], e027. https://doi.org/10.3989/ mc.2014.07913.

22. Ayar, P.; Moreno-Navarro, F. Rubio-Gamez, M.C. (2016) The healing capability of asphalt pavements: a state of the art review. J. Cleaner Prod. 113, 28-40. https://doi. org/10.1016/j.jclepro.2015.12.034.

23. Ayar, P.; Moreno-Navarro, F.; Sol-Sanchez, M.; RubioGamez, M.C. (2018) Exploring the recovery of fatigue damage in bituminous mixtures: the role of rest periods. Mat. Struct. 51 [1], 25. https://doi.org/10.1617/ s11527-018-1146-7.

24. Moreno-Navarro, F.; Ayar, P.; Sol-Sanchez, M.; RubioGamez, M.C. (2017) Exploring the recovery of fatigue damage in bituminous mixtures at macro-crack level: the influence of temperature, time, and external loads. Road Mat. Pavement Design 18, 293-303. https://doi. org/10.1080/14680629.2017.1305149.

25. Moreno-Navarro, F; Sol-Sanchez, M. Rubio-Gamez, M.C. (2015) Exploring the recovery of fatigue damage in bituminous mixtures: the role of healing". Road Mat. Pavement Design 16 [Issue sup1: EATA], 75-89. https:// doi.org/10.1080/14680629.2015.1029706.

26. Roman, C.; Garcia-Morales, M. (2017) Linear rheology of bituminous mastics modified with various polyolefins: a comparative study with their source binders. Mat. Struct. 50 [1], 86. https://doi.org/10.1617/s11527-016-0953-y.

27. Safaei, F.; Hintz, C. (2014) Investigation of the effect of temperature on asphalt binder fatigue. In: Asphalt
Pavements, Proceedings of the international conference on asphalt pavements (Rayleigh) 1, (2014), 1491-1500.

28. Artamendi, I.; Khalid, H. (2004) Different approaches to depict fatigue of bituminous materials. In: Proceedings of the 15th European Conference of Fracture (Stockholm), (2004).

29. Van Dijk, W.; Moreaud, H.; Quedeville, A.; Uge, P. (1972) The Fatigue of Bitumen and Bituminous Mixes. In: Proceedings of the Third International Conference on the Structural Design of Asphalt Pavements (London) 1, (1972), 354-366.

30. Qiu, J.; van de Ven, M.; Wu, S.; Yu, J.; Molenar, A. (2012) Evaluating Self Healing Capability of Bituminous Mastics. Exper. Mech. 52, 1163-1171. https://doi.org/10.1007/ s11340-011-9573-1.

31. Yuliestyan, A.; Cuadri, A.A.; García-Morales, M.; Partal, P. (2016) Influence of polymer melting point and Melt Flow Index on the performance of ethylene-vinyl-acetate modified bitumen for reduced-temperature application. Mat. Design 96, 180-188. https://doi.org/10.1016/j. matdes.2016.02.003.

32. Yousefi A.A. (2003) Polyethylene dispersions in bitumen: The effects of the polymer structural parameters. $J$. Appl. Polym. Sci. 90, 3183-3190. https://doi.org/10.1002/ app. 12942 .

33. Polacco, G.; Filippi, S.; Merusi, F.; Stastna, G. (2015) A review of the fundamentals of polymer-modified asphalts: Asphalt/polymer interactions and principles of compatibility. Adv. Colloid. Interface Sci. 224, 72-112. https://doi. org/10.1016/j.cis.2015.07.010. 